\title{
Danceterias como espaço de lazer: o cenário legislativo posterior ao desastre na boate KISS
}

\author{
Thaiane Bonaldo Nascimento' \\ Elizara Carolina Marin²
}

\section{RESUMO}

Este estudo objetiva analisar as ações do poder público para com os estabelecimentos privados de lazer (danceterias) no âmbito da legalidade, posterior ao desastre na Boate KISS. Utilizamos como caminho a Análise Documental, como a Lei Complementar $\mathrm{n}^{\circ}$ 14.376, de 26 de dezembro de 2013, o Inquérito Policial da Boate KISS e a mídia impressa Diário de Santa Maria e, a Análise de Conteúdo. Inferimos a mobilização do poder público, posterior ao desastre, na criação de legislações que garantissem a segurança nas danceterias, em especial a Lei Kiss, bem como sua flexibilização, explicitando que o sistema econômico e interesses privados são balizadores da política e das relações entre o público e o privado. O desastre da Boate KISS registra a gravidade de riscos na esfera do lazer e nas tecnologias que incitam desejos, a necessidade de garantia de direitos sociais e de equidade social.

Palavras-chave: Lazer mercadoria. Legislação. Poder público. Danceterias

1 Mestre em Educação Física. Prefeitura Municipal de Toropi (PMT). Toropi/Rio Grande do Sul, Brasil. E-mail: thaianebonaldo@yahoo.com.br

2 Pós-doutorado na Università degli Studi di Roma "La Sapienza". Universidade Federal de Santa Maria (UFSM). Santa Maria/Rio Grande do Sul, Brasil. E-mail: elizcarol@yahoo.com.br.

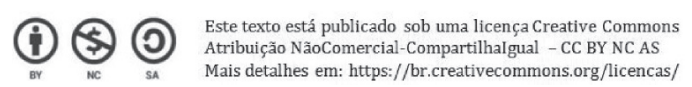


Dance clubs as leisure space: the legislative scenario after the disaster at KISS nightclub

\begin{abstract}
This study aims to analyze the actions of the public power towards private leisure establishments (dance clubs) in the scope of legality, after the disaster at KISS Nightclub. We used as a way the Document Analysis (Complementary Law $n^{\circ} 14.376$, of December 26, 2013, the Police Investigation of the KISS Nightclub and the print media Diário de Santa Maria) and the Content Analysis. We inferred the mobilization of the public power, after the disaster, in the creation of legislations that would guarantee safety in the dance clubs, especially the Kiss Law, as well as its flexibility, explaining that the economic system and private interests are benchmarks of politics and of the relations between the public and the private. The KISS Nightclub disaster registers the seriousness of risks in the leisure sphere and in the technologies that incite desires, and the need to guarantee social rights and social equity.
\end{abstract}

Keywords: Merchandise leisure. Legislation. Public power. Dance clubs

Discotecas como espacios de ocio: el escenario legislativo posterior al desastre en la boate Kiss

\title{
RESUMEN
}

Este estudio objetiva analizar las acciones del poder público hacia establecimientos privados de ocio (discotecas) en el ámbito de la legalidad posterior al desastre en la Boate Kiss. Utilizamos como instrumento el Análisis Documental de la Ley Complementar $\mathrm{n}$. $^{\circ}$ 14.376, de 26 de diciembre de 2013, la investigación policial de la Boate Kiss, noticias del periódico Diário de Santa Maria, y el análisis de contenido. Inferimos la movilización del poder público, posterior al desastre, en la creación de legislaciones que garanticen la seguridad en discotecas, en especial la Ley Kiss y su flexibilización, evidenciando que el sistema económico e intereses privados son balizadores de la política y de relaciones entre el público y el privado. El desastre de la Boate Kiss registra la gravedad de riesgos en el ámbito del ocio y en las tecnologías que incitan deseos, la necesidad de garantía de derechos sociales y de equidad social.

Palabras clave: Ocio mercantilizado. Legislación. Poder público. Discotecas 


\section{INTRODUÇÃO}

O desastre que ocorreu na Boate $\mathrm{KISS}^{3}$, na cidade de Santa Maria/RS, no ano de 2013, que resultou em 242 vítimas fatais, advertiu que o lazer da esfera privada, no caso específico das danceterias, carece de um olhar para além da estética. A subordinação do lazer à forma de mercadoria vem se expressando como padrão dominante nas vivências dos indivíduos, o que emerge a necessidade de aprofundarem as discussões sobre este e sua relação com o poder público no âmbito científico.

As danceterias compõem o panorama do lazer santa-mariense, as quais lançam mão de arquitetura moderna, estilos musicais em alta, no contexto midiático, e de estratégias publicitárias para instigar seu consumo. A Boate KISS, até o fatídico 27 de janeiro de 2013, constituía-se em um dos principais espaços de lazer, inovando com tecnologias produtoras de sensações. Entretanto, a arquitetura do prédio e suas instalações eram repletas de irregularidades, como aponta o estudo de Nascimento e Marin (2015).

O complexo fenômeno ocorrido com a Boate KISS descortinou os riscos existentes no pacote hedonista criado pelo lazer mercadoria; registrou que infrações às normas de segurança, pela obsessão da maximização de lucros, resultam em óbitos; e trouxe à tona a necessidade de olhar com seriedade as promessas de felicidade, em particular, as de danceterias.

Nessa direção, o objetivo deste artigo é analisar as ações do poder público para com os estabelecimentos privados de lazer (danceterias) no âmbito da legalidade, posterior ao desastre na Boate KISS. Utilizamos como caminho a Análise Documental da Lei Complementar $n^{\circ}$ 14.376, de 26 de dezembro de 2013 (Lei Kiss), o Inquérito Policial da Boate KISS (IPBK) e a mídia impressa do jornal Diário de Santa Maria (DSM). Estes instrumentos foram elencados por abarcarem o cenário do desastre da Boate KISS e ações posteriores, fornecendo perspectivas diversas.

Delimitamos como escopo as matérias da mídia impressa DSM que possuem relação com a temática no período de vinte e sete (27) de janeiro de 2013 à trinta e um (31) de dezembro de 2014. Por meio de leitura aprofundada dos títulos e conteúdo das matérias, selecionamos duzentas e oitenta e duas (282) matérias, relativas ao ano de 2013 e noventa e uma (91) relativas ao ano de 2014.

Para interpretação dos dados, advindos dos documentos, nos inspiramos nos pressupostos da Análise de Conteúdo, a luz de Franco (2005). Em suma, elencamos como categorias para análise dos documentos: lazer mercadoria, danceterias e legislação.

\section{Lazer mercadoria: as danceterias de Santa Maria/RS}

O consumo de mercadorias começa a significar, nas palavras de Padilha (2006, p.135), um mergulho em "fantasias e status social, na medida em que os objetos passaram

3 Pesquisa financiada pela Coordenação de Aperfeiçoamento Pessoal de Nível Superior (CAPES); 
a ser adquiridos não pelo seu valor de uso, mas, pelo significado social de sua posse". Nessa lógica, as recorrentes inovações na Indústria do Entretenimento mantêm um frenético círculo de produção e acumulação de mercadorias, que contribuem para associar o lazer à "equipamentos", principalmente no contexto urbano, com inúmeros investimentos em shopping centers, bares, danceterias e marketing para a venda (MARIN; PADILHA, 2007).

A partir do exposto, entendemos o lazer, à luz de Mascarenhas (2005, p.26), como um fenômeno contraditório, determinado pelo jogo das forças sociais, pois "envolve não só a alegria do lúdico, a fruição, a fantasia, o prazer estético e a experiência criativa, mas, também, a satisfação imediata, a utilidade prática, o lucro e a alienação". Contraditoriamente, tanto é tempo, e tempo mercadorizado, quanto "tempo e espaço para o exercício da cidadania e prática da liberdade" (MASCARENHAS, 2001, p.54), ou ainda como expõem Padilha (2006) o lazer é tanto tempo para consumo manipulado que prioriza os lucros, quanto possibilidade de tempo de reflexão e práxis.

É sob a forma mercadoria que o lazer vem ganhando ênfase, permeado pela alienação e fetichização, invadindo subjetividades, coletividades e impelindo à sujeição ao mercado. A Indústria do Entretenimento passa a ser uma ponte do capital para consolidar o consumo exacerbado de mercadorias. Mascarenhas (2003, p. 126) alude que o mercado surge como um verdadeiro professor, com uma linguagem "hipnótica e universal, que sinaliza e gesticula, com sua mão invisível", para a busca do interesse próprio, o amor ao dinheiro, o apetite insaciável por bens, a satisfação pessoal e imediata, a escravidão ao consumo".

Evidencia-se uma ordem do sistema capitalista para a ampliação e efetivação do lazer sob a forma mercadoria, dificultando a concretização de alternativas. Ademais, as condições materiais dos lazeres públicos não favorecem que os sujeitos exerçam efetiva e amplamente à experimentação da multiplicidade de gostos estéticos e de conteúdos culturais. Tal realidade figura uma desordem na dimensão lúdica, crítica, educativa do lazer, pois as políticas públicas não atendem essa demanda, afinal requerem compromisso econômico, repercutindo na desintegração dos direitos sociais.

A cidade de Santa Maria adentra a lógica mercadológica de lazer, pois não tem investido em políticas públicas que garantam espaços, equipamentos, segurança e profissionais qualificados para o lazer, conforme aponta a pesquisa de Denardin e Silva (2010). Como complementa Saldanha (2003), os espaços e serviços públicos da cidade têm sido sucateados, tratados como não necessário; além de não comportar as singularidades de cada bairro. Com isso, corrobora com a preferência dos indivíduos pelo lazer mercadoria.

Nestes meandros, a Indústria do Entretenimento realiza investimentos para seduzir. $\mathrm{Na}$ busca de conquistar e manter a clientela, as empresas de lazer renovam-se constantemente, produzem e saciam desejos, ditam modas, formas de prazer e fomentam o consumo desprovidos de um olhar crítico. Um dos elementos vem a ser composição estética externa e interna das edificações, a exemplo das danceterias. Afinal, sedução, luxo e satisfação são algumas das variáveis mercadológicas que contribuem para os usuários preferirem uma danceteria à outra. 
Vivenciar o espetáculo de sons e luzes proporcionado pelas danceterias produz a fuga do mundo real e a imersão em um mundo de fantasias e de sonhos, o que torna a alienação ainda mais presente. Não resta dúvida, como assinala Mascarenhas (2005), que os estímulos patrocinados pela publicidade exaltam o invólucro e a aparência das mercadorias, elevando, sobremaneira, o seu poder de atração.

A Boate KISS procurou inovar com tecnologias produtoras de sensações. Por exemplo, foi a única da cidade a possuir um painel de bolhas iluminado com lâmpadas de Led, em que se criavam efeitos visuais incomuns. Um serviço diferenciado e ofertado pela boate era a área vip. O referido espaço era reservado dentro da danceteria para clientes que pagavam valores mais elevados, para receber atendimento especial. Estar na área vip é sinônimo de status social, o que instiga vivenciar este espaço. Ademais, esta área da danceteria representa a divisão de classes sociais, tendo em vista que os equipamentos de lazer são mantidos de acordo com as normas da sociedade capitalista.

O desastre ocorrido na Boate KISS revela que as fachadas estéticas das danceterias e de outros estabelecimentos de lazer não constituem apenas hedonismo, mas riscos para além do visível. O desastre mostrou tensões entre o público e o privado, no âmbito do lazer, e trouxe à tona a necessidade de voltarmos o olhar para como a segurança é encarada pelos órgãos públicos e pelos proprietários de estabelecimentos privados.

Os proprietários por meio de campanhas publicitárias e investimentos arquitetônicos, revestem seus estabelecimentos de liberdade e felicidade plena, induzindo ao consumo. Os frequentadores sedentos por novas experiências e momentos de lazer são convencidos de que a superlotação, o consumo de bebidas alcoólicas, os artefatos pirotécnicos são parte do lazer, não questionando seus riscos. Entretanto, este invólucro escamoteia uma imensidão de pressupostos ideológicos, que nas condições em que se apresenta não pode fornecer mais do que a ilusão de plenitude e de lazer por tempo determinado.

A adesão acrítica ao lazer mercadoria leva ao consumo não somente de produtos, mas, como também de atitudes. Isso contribui para que as festas, mais especificamente as privadas, consolidem-se como espaço de reunião, sendo muito mais divertidas com mais pessoas congregando. Como aponta Beck (2011, p.56, grifos do autor), os riscos surgem, sobretudo, na ambivalência da sociedade de mercado desenvolvida, pois não são apenas riscos, "são também oportunidades de mercado. É precisamente com o avanço da sociedade de risco que se desenvolvem como decorrência as oposições entre aqueles que são afetados pelos riscos e aqueles que lucram com eles".

No que tange ao lazer privado, os riscos não podem ser ignorados e/ou banalizados. Nestes espaços sua invisibilidade se acentua, pois, os frequentadores, normalmente, não consideram os fatores de risco e não detêm conhecimento sobre as normas de segurança estabelecidas pela legislação, demandando atenção para além das fachadas estéticas e das promessas de diversão. Beck (2011, p. 89) alerta que "o mundo das coisas visíveis precisa ser questionado, relativizado e avaliado em termos de uma realidade presumida, mas também de uma segunda realidade oculta". Esta última garante a malvadeza dos riscos um espaço praticamente ilimitado. 
O desastre na Boate KISS visibilizou as brechas existentes nas legislações e a dificuldade dos governos (federal, estadual e municipal) em efetivar processos de fiscalização de estabelecimentos privados, pois tanto o processo de abertura quanto de manutenção da danceteria esteve envolto de irregularidades. Mesmo, diante de irregularidades, a boate manteve-se em funcionamento durante três anos e sete meses, destacando-se na conjuntura de empreendimentos de lazer da cidade de Santa Maria.

A indiferença dos órgãos públicos, dos estabelecimentos privados e dos frequentadores para com os riscos ancora-se no terreno cultural e político arraigado, contribuindo para que desastres, como o da Boate KISS, tornem-se realidade. No entanto, a corrida para sanar os riscos, visíveis e "invisíveis" aos olhos dos frequentadores, a exemplo dos alvarás, deve ser travada pelos órgãos públicos e se consolidar como uma ação constante, como uma política pública efetiva. Afinal, como explana Beck (2011, p.54), o “que escapa à percepção não coincide com o irreal, possuindo um elevado grau de concretude em termos de ameaça", a exemplo do desastre na Boate KISS.

\section{Ações do poder público posterior ao desastre na Boate KISS}

A pergunta norteadora, posterior ao desastre na Boate KISS, é: como os órgãos públicos vêm se posicionando para sanar irregularidades legislativas das danceterias?

Podemos sinalizar que o primeiro movimento de luta em prol da segurança nas danceterias emergiu da sociedade civil. Este teve como ponto de partida a busca pela efetivação das legislações existentes e criação de novas. Coutinho (2011) assinala que as situações da realidade efetiva justificam uma iniciativa de vontade.

Nestes meandros, o Estado assume papel central nesta discussão, pois tanto a efetivação da segurança quanto dos riscos está diretamente relacionada às suas ações, seja pela forma de aplicar a legislação existente, seja pela omissão ou conivência com a hegemonia exercida pelos setores privados da sociedade. Como elucida Beck (2011, p.275) os riscos são produtos históricos, a imagem das ações e omissões humanas e, expressão de forças produtivas altamente desenvolvidas.

A primeira ação dos órgãos públicos, pós-desastre, em prol da segurança foi interditar todas as danceterias de Santa Maria por um período de 30 dias, seguida da criação de uma força-tarefa para fiscalizar estabelecimentos promotores de eventos com aglomeração de pessoas. Neste período, bares e boates, que há tempos não recebiam vistoria, foram fiscalizados com a intenção de adequar a documentação, como destaca a matéria: "A corrida pela fiscalização" (DSM, 27 e 28-04-2013). A força-tarefa procurou acompanhar a situação em que se encontrava a cidade, incentivando e fomentando uma cultura de fiscalização.

A intensidade de fiscalizações resultou, no ano de 2013, em uma sequência de fechamentos de estabelecimentos devido às irregularidades, de modo que alguns não retornaram as atividades. No ano de 2014 as fiscalizações mantiveram a efetividade e bares e danceterias vivenciaram um constante abrir e fechar de portas, em detrimento 
de irregularidades em suas edificações e em alvarás como: Plano de prevenção contra incêndios (PPCI), Habite-se ${ }^{4}$ e Alvará de Localização.

Uma vez que as fiscalizações continuam encontrando irregularidades nos estabelecimentos, evidencia-se que os proprietários não criaram a consciência de que a segurança é elemento fundamental para o lazer de qualidade.

A análise do IPBK e das matérias jornalísticas permitiu inferir sobre a fragilidade da fiscalização nos empreendimentos de lazer na cidade de Santa Maria. O foco da fiscalização municipal resumia-se na verificação de documentos e na conferência da arrecadação das taxas referentes ao licenciamento dos estabelecimentos. Isto é, se durante o período de funcionamento, a Boate KISS não estava com os alvarás consoantes à legislação - além de outros problemas já citados - a fiscalização cobrou somente os alvarás, denunciando a vulnerabilidade dos setores públicos na regulamentação e vigilância legislativa sobre o setor privado.

Somado a isto, as brechas legislativas dificultaram o fechamento de danceterias, pois, na lógica do tempo é dinheiro, ainda que a danceteria fosse lacrada o proprietário poderia reabri-la e assumir as multas por descumprir a determinação. Evidencia-se, que na relação entre segurança e risco, a produtividade e a lucratividade destacam-se.

Ademais, havia um processo de precarização dos órgãos públicos de fiscalização, contribuindo para a falta de segurança dos espaços de lazer. Realidade explicitada nas matérias: "Os fiscais temem serem responsabilizados" (DSM, 12-02-2013) e; "A fiscalização da prefeitura está muito sucateada e amordaçada.". Referente a isto, a matéria: "Fiscalização se limita a documentos" (DSM, 12-02-2013), menciona que os fiscais não recebiam treinamento adequado para identificar situações de risco. Em suma, o descaso com os sistemas de fiscalização reflete uma cultura que não apresenta como cerne o ser humano e suas necessidades primordiais.

Conforme adverte a matéria, "Boate não cumpria requisitos" (DSM, 29-01-2013) um dos pontos mais questionáveis e relevantes para compreender os problemas apresentados na danceteria, é apurar as causas da tragédia e porque as autoridades menosprezam os problemas estruturais considerados graves por especialistas. Não obstante serem graves o suficiente para exigir mudanças centradas nas necessidades humanas, naquele momento, pôde-se constatar descaso do poder público em fiscalizar.

O desastre da Boate KISS foi um prenúncio de consciência sobre os riscos. Conforme a matéria, "A lei e a realidade" (DSM, 12-04-2014), constituiu, na combinação de irresponsabilidade e de ganância. As causas podem ser encontradas na falta ou no não cumprimento da legislação, somados à omissão das autoridades com a atribuição de prevenir e fiscalizar. Nessa direção, evidencia-se a necessidade de rigor e avanços na política de segurança e de fiscalizações públicas para que os estabelecimentos não exerçam atividades irregularmente. Para tanto, torna-se pertinente que os sistemas de fiscalizações e concessões de alvarás sejam entendidos como fundamentais tanto como a qualificação

$4 \mathrm{O}$ PPCl, Habite-se e Alvará de Localização tratam-se de alvarás obrigatórios aos estabelecimentos. A falta destes ou o vencimento de sua validade resultam no fechamento do estabelecimento até regularização. 
dos profissionais que atuam nessa esfera. Afinal, os riscos, mais do que ameaças, são fatos e, estabelecer um conjunto de políticas e medidas preventivas dos riscos é uma demanda urgente. No centro da questão está a negação da coisificação dos sujeitos sociais e da fetichização dos empreendimentos de lazer.

A população santa-mariense vem contribuindo para ações de fiscalização nas danceterias, por meio de denúncias, o que enseja possível mudança em seu comportamento e na acepção sobre o lazer. Exemplos disto, em julho de 2014 frequentadores de uma danceteria encaminharam um vídeo ao DSM que visibilizava o seu funcionamento, mesmo com a saída de emergência bloqueada por um tapume junto à calçada, já que estava em obras.

Entretanto, as denúncias não se apresentam como único esteio a segurança dos frequentadores, mas também interesses econômicos. Destaca a matéria: "Prefeito diz que a cidade vive numa época de denuncismo" (DSM, 28-07-2014). Segue a matéria elucidando que:

\footnotetext{
"O "denuncismo" é uma prática corrente, não só em Santa Maria. Por interesses econômicos, as pessoas utilizam o poder público para gerar problemas aos concorrentes, principalmente, entre donos de bares e boates. Mas, o que prevalece, na prefeitura, é o cumprimento da lei e o bom senso. Não pode, o poder público, ser instrumento de disputas e interesses econômicos. O município tem o cuidado com a segurança e o bem-estar da população, sem coibir a atividade econômica (DSM, 28-07-2014)".
}

Esta declaração revela que o capitalismo impele o ser humano ao estado de sujeição, dificultando o olhar para os semelhantes com foco desvinculado do lucro. Ainda, expressa que um desastre arrebatador não é suficiente para superação da lógica mercadológica imbricada no lazer. Bem como, não é suficiente para emergir a consciência de que o dinheiro não paga vidas humanas. Conforme expressa Padilha (2008, p.110), como pode o ser humano "ser livre quando a sociedade e as relações sociais são apagadas diante de um mercado mandão que ganha uma aparência concreta por meio do dinheiro?".

Todavia, o desastre na Boate KISS resultou em processos de fiscalização, na revisão da legislação existente e na criação de novas legislações. Tais ações foram ancoradas pelos anseios da população, pois, como bem assinala Beck (2011), um dos fatores que pode quebrar o feitiço da invisibilidade dos riscos são as experiências pessoais. Ademais, realçam Spink (2002a) Pontes (2011) e Guiddens (2007, p.43), que o risco está vinculado a estratégias de poder, e "com o desenvolvimento dos riscos fabricados os governos não podem fingir que esse tipo de administração não lhes compete".

Dentre as conquistas no âmbito legislativo municipal podemos citar a Lei Complementar 096, de 13 de janeiro de 2014, que acrescenta o artigo 41A ao Código de Posturas do município. A lei foi sancionada a fim de extinguir a superlotação, obrigando aos estabelecimentos de diversão noturna com aglomeração de pessoas, como casas de shows e de espetáculos, sem assentos marcados para a totalidade de público, instalar um dispositivo eletrônico de contagem simultânea de pessoas. 
O referido equipamento deve manter-se em funcionamento da abertura até o encerramento das atividades, em local visível ao público, bem como indicar a capacidade total da danceteria de acordo com o laudo populacional e em conformidade com o $\mathrm{PPCl}$. A lei também estabelece que na medida em que for atingida $95 \%$ da capacidade de lotação do estabelecimento, o proprietário deverá iniciar procedimentos para que a mesma não seja ultrapassada. Os registros de entrada e saída de pessoas carecerão de ser preservados por meio do dispositivo por no mínimo 120 dias (cento e vinte), para fins de consulta e fiscalização.

Outro marco legislativo em prol da segurança nos estabelecimentos de lazer em âmbito nacional foi a assinatura da portaria 3.083, do Ministério da Justiça, que procura melhorar as informações de segurança junto aos consumidores. Para tal, prevê que todos os estabelecimentos de lazer, cultura e entretenimento do país divulguem nos ingressos e nas entradas dos prédios os alvarás de funcionamento e dos bombeiros com datas de validade e capacidade de lotação. Com isso, constitui-se numa forma de dar conhecimento aos frequentadores sob os aspectos que garantem sua segurança nos momentos de lazer, o que não significa que todos atentarão para tais elementos, afinal, ações legislativas não são suficientes para tomada de consciência sobre a segurança.

A preocupação da sociedade para com a utilização de artefatos pirotécnicos nas danceterias resultou na elaboração de projetos de leis, uma vez que no ordenamento jurídico santa-mariense não existia uma legislação específica para o uso destes no interior das danceterias. Os referidos projetos apresentam um artigo ou parágrafo único que estabelece a proibição dos artefatos pirotécnicos em estabelecimentos que funcionem em locais fechados, pois, como ressalta Spink, Medrado e Mello (2002b), à medida que a confiança na capacidade de gerenciar riscos começa a desaparecer, tendo em vista a complexidade dos mesmos, a fatalidade assume novos contornos, especialmente dos riscos decorrentes das novas tecnologias. Segue os projetos:

Projeto de Lei $N^{\circ}$ 4.923, de 2013 Dispõem sobre as obrigações que devem ser observadas por proprietários, administradores e responsáveis por boates, casas de shows, bares, restaurantes e estabelecimentos congêneres, que funcionem em locais fechados estabelecendo maior rigor para a liberação de seus alvarás de funcionamento.

Projeto de Lei No 4.924, de 2013 Dispõe sobre segurança em casas noturnas; 65.

Projeto de Lei № 4,949 de 2013 Estabelece normas de prevenção e proteção contra incêndios boates e casas de shows e outras providências.

Projeto de Lei № 4.952 de 2013 Dispõe sobre a obrigatoriedade de equipe de primeiros socorros e define as normas de segurança em Casas de Espetáculos.

Contudo, o maior marco legislativo derivado do desastre foi a Lei Estadual de Prevenção de Incêndios nas edificações e áreas de risco, denominada "Lei Kiss". A sanção 
desta lei foi um divisor de águas para a segurança contra incêndios no Brasil, pois objetiva preservar e proteger a vida dos ocupantes das edificações e áreas de risco; estabelecer um conjunto de medidas eficientes de prevenção contra incêndio; dificultar a propagação do incêndio, preservando a vida, reduzindo danos ao meio ambiente e ao patrimônio; proporcionar meios de controle e extinção do incêndio; dar condições de acesso para as operações do Corpo de Bombeiros Militar do Estado Rio Grande do Sul (CBMRS); proporcionar a continuidade dos serviços nas edificações e áreas de risco de incêndio; definir as responsabilidades e competências de legislar em âmbito estadual, respeitando as dos demais entes federados; estabelecer as responsabilidades dos órgãos competentes pelo licenciamento, prevenção e fiscalização contra incêndios e sinistros deles decorrentes; definir as vistorias, os licenciamentos e as fiscalizações as edificações e áreas de risco de incêndio; determinar as sanções nos casos de descumprimento desta Lei Complementar (Lei Complementar $\mathrm{n}^{\circ}$ 14.376, de 26 de dezembro de 2013).

A lei também prevê, no âmbito do estado do RS, o "Conselho Estadual de Segurança, Prevenção e Proteção Contra Incêndio" (COESPPCI), que se constitui no órgão superior normativo e consultivo para os assuntos abarcados na lei. Atribui ao conselho atualizar as tabelas técnicas das normas de segurança embasadas em pesquisas, bibliografias e aprovação dos seus membros. A fim de auxiliar o órgão supracitado e o cumprimento da legislação, foi criado o "Conselho Regional de Segurança, Prevenção e Proteção Contra Incêndios (CORPPCI)", o qual se constitui nos moldes do primeiro, e instala-se onde houver os Comandos Regionais de Corpo de Bombeiro Militar do Rio Grande do Sul (CRBMRS).

A Lei Kiss também estabelece ser de competência do CBMRS, regulamentar, analisar, vistoriar, fiscalizar, aprovar as medidas de segurança, expedir o Alvará do PPCl, bem como aplicar as sanções previstas e pesquisar medidas de segurança contra incêndio em edificações e áreas de risco. Institui como competência do CBMRS realizar vistorias ordinárias e extraordinárias, de acordo com a ocupação e uso das edificações. As primeiras dar-se-ão por ocasião da liberação e da renovação do Alvará de $\mathrm{PPCl}$, que no caso das danceterias, serão anuais. As vistorias extraordinárias dar-se-ão a partir de denúncia de irregularidades ou em atividades de fiscalização organizadas através da iniciativa dos órgãos públicos competentes.

É de competência do CBMRS e do município, ao constar riscos aos usuários e ao funcionamento da edificação, efetivar sua interdição. Para tanto, deve expedir uma notificação ao proprietário ou responsável, estabelecendo orientações, apresentando exigências, indicando os itens de infração e fixando prazo para seu integral cumprimento, com vista a sua regularização junto à Administração Pública.

A Lei Kiss adotou um conjunto de medidas de segurança para evitar incêndios e proteger a vida, o meio ambiente e o patrimônio. As medidas são as seguintes:

Art. 36. As edificações e as áreas de risco de incêndio serão dotadas das seguintes medidas de segurança, que serão fiscalizadas pelo CBMRS:

I - restrição ao surgimento e propagação de incêndio;

II - resistência ao fogo dos elementos de construção;

III - controle de materiais de acabamento; 


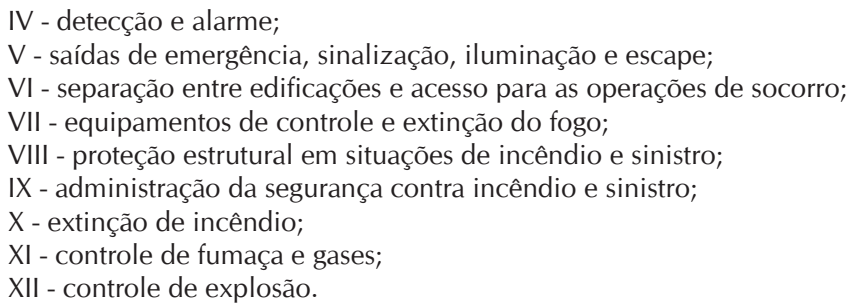

Penalidades e sanções administrativas também são evidenciadas pela Lei Kiss, as quais serão aplicadas em detrimento de seu descumprimento, dentre elas estão: advertência, multa, interdição e embargo. As advertências, multas e interdições são de aplicabilidade do CBMRS ao proprietário ou responsável pelo uso da edificação, em conformidade com a gravidade das infrações. Ao município compete embargar as edificações cujos proprietários ou responsáveis não tenham observado a legislação.

A criação das leis supracitadas comprova que os direitos sociais ajustam suas velas, nas palavras de Beck (2011), não voluntariamente, mas com o vigoroso apoio das ruas e da política. Foi necessário a Sociedade Civil tomar para si as rédeas e colocar os governantes no banco de réus, pleiteando sua inocência em detrimento das falhas políticas que mantiveram a Boate KISS em funcionamento, para efetivação de novas leis. Não obstante, a criação das leis não se constituiu em um feito catártico, pois, não foram sancionadas pela consciência dos governantes e governadas, mas resultante de um desastre.

Não podemos negar que a sanção de novas leis e o aprimoramento dos processos de fiscalização constitui um marco referente à segurança em danceterias. No entanto, sua aceitabilidade não se deu em primeira instância, pois os proprietários dos estabelecimentos privados e as prefeituras efetivaram constantes reclamações devido às dificuldades e aos custos para adequar-se às normas. Fator este que contribuiu para a flexibilização da Lei Kiss e demonstrou que o predomínio de uma ou de outra ação política, segundo Coutinho (2011), é decisivo para determinar que classe ou grupos de classes exercem hegemonia em uma situação concreta e como o faz.

A flexibilização da lei incidiu na ampliação de: 200 (duzentas) para 400 (quatrocentas) pessoas para ter a obrigatoriedade de bombeiros ou de policiais da Brigada Militar nos eventos ${ }^{5}$; de $750 \mathrm{~m}^{2}$ para $1500 \mathrm{~m}^{2}$ na área de estabelecimentos que poderiam apresentar Plano Simplificado de Proteção contra Incêndio. Aos municípios foi permitido emitir alvarás provisórios de funcionamento para locais de menor risco, e passou a ser o responsável para acompanhar a regularidade das licenças. Com a finalidade de sua revogação ou expedição de alvará definitivo, condicionado à apresentação do alvará dos bombeiros. Tal realidade

5 Devemos considerar a importância dos bombeiros e agentes da Brigada Militar para a segurança dos estabelecimentos de lazer. Todavia tratam-se de categorias que vêm sofrendo precarização nas condições de trabalho no que se refere aos salários, à estrutura e ao número de efetivos. É sabido que o número de cidades do RS que têm incorporado um posto do Corpo de Bombeiros é ínfimo. Perguntamos: como os estabelecimentos conseguirão a presença dos mesmos em seus eventos? 
contribui para a manutenção de fragilidades nos sistemas de fiscalização e segurança dos estabelecimentos. Visto que a lei não determina prazo máximo de validade do alvará provisório, como expressa a matéria: "Entenda as alterações na Lei Estadual" (DSM, 23-8-2014).

Evidencia-se que a Lei Kiss não foi um movimento ético-político, mas uma ação momentânea para acalmar e suprir as demandas dos governados, em outras palavras, uma práxis manipulatória. O desastre na Boate KISS e a flexibilização da Lei Kiss é a síntese da barbárie capitalista, em que o valor da vida humana é aquém aos interesses dos proprietários e do lucro.

Posterior as mudanças na legislação, a pergunta que se coloca é: As danceterias garantem a segurança dos usuários? No transcorrer do ano de 2014 o DSM visitou os estabelecimentos de lazer, em especial as danceterias, constatando que a maioria das leis criadas posterior ao desastre na Boate KISS não emplacou. De cinco danceterias visitadas, no mês de janeiro, foi constatado que nenhuma possuía todas as informações solicitadas pela Portaria 3.083 e, apenas uma informava a lotação e dados do $\mathrm{PPCl}$ nos ingressos ou entrada dos prédios.

O órgão responsável por fiscalizar a portaria seria o Procon. Entretanto, no município há apenas dois fiscais para atender toda a demanda. Sendo assim, segundo relatos da matéria, "Precisa melhorar muito", publicada em 07-01-2014, "mesmo que todos os locais estivessem cumprindo o que determina a lei, o que não está ocorrendo, não haveria como se certificar, já que o Procon diz não ter profissionais suficientes para atuar", restando a ele agir mediante denúncia ou em blitz eventos. De acordo com a fala proferida por um juiz ao DSM: “Estão se acumulando normas jurídicas inexequíveis e inaplicáveis, por falta de estrutura física e de pessoal, que são criadas apenas para que as pessoas achem que os problemas foram resolvidos" (PRECISA MELHORAR MUITO, DSM, 07-01-2014).

As matérias analisadas expressam que a exigência de alvarás em locais visíveis e de informações sobre lotação em convites/ingressos está sendo cobrada às danceterias santa-marienses. Já, a proibição de comandas em estabelecimentos com mais de 250 pessoas não vem sendo totalmente respeitada, de modo que bares com capacidade superior seguem usando uma comanda de papel para anotar o consumo dos frequentadores (Dois sustos, nenhum responsável, 28-07-2014; Maioria das regras não emplacou, 05-12-2014).

A instalação dos placares eletrônicos de controle de público também não faz parte da realidade do lazer santa-mariense. Para contabilizar o público, os proprietários vêm lançando mãos de estratégias como: software que emite tíquetes aos clientes; comanda eletrônica que utiliza pulseiras com código de barras e contagem de ingressos vendidos, que são depositados em uma urna.

A ausência dos aparelhos se justifica, por parte dos proprietários, pelo valor de sua instalação. Ademais, alguns proprietários entendem a instalação do equipamento, como uma desresponsabilização do Estado para com a fiscalização, o que se expressa na seguinte fala:

\footnotetext{
“Na realidade, alguns órgãos não querem mais vida noturna em Santa Maria. Estão criando leis para não se responsabilizar. Na minha opinião, essa lei não deveria ter sido sancionada. Não é um aparelho que vai fazer o empresário criar a consciência
} 
de que não deve ultrapassar a lotação. Tenho certeza que as casas noturnas que estão funcionando clandestinamente vão continuar burlando a legislação. Deveriam criar uma lei que coloca um fiscal competente fazendo essa contagem" (DSM, O QUE DIZEM, 21-01-2014).

A fala demostra, mais uma vez, que a segurança não é um balizador na vivência do lazer. Se a criação de leis não é indício de consciência da população para sua necessidade e finalidade, quiçá dos empresários, que devem realizar investimentos para adequação de seus estabelecimentos e esperar as fiscalizações, que não são ágeis, dar-lhes novamente o aval para exercer suas atividades. Como elucida Beck (2011), o esforço pelo aumento da produtividade sempre deixou de lado os riscos implicados, de modo que a produção dos mesmos tem seu primeiro fundamento em uma miopia econômica.

\section{CONSIDERAÇÕES FINAIS}

Abordar como temática um desastre que arrebatou o Brasil e que estará na história da cidade de Santa Maria, exigiu esforço analítico, cautela e constante afastamento emocional - embora, nem sempre possível. A temática é pungente, todavia, demanda investimento científico, a fim de sinalizar, sob a ótica adotada neste estudo, as contradições do lazer mercadoria e das relações entre poder público e privado.

Evidenciamos que a Boate KISS era sustentada por meio de uma engenharia de consenso na qual irregularidades, a exemplo da superlotação, alvarás e infraestrutura interna, eram pautadas na busca dos proprietários pelo lucro e na negligência/precarização da participação estatal no cumprimento da legislação pelo âmbito privado. No entanto, a danceteria funcionava sob a aparência da legalidade. Afinal, os riscos no âmbito legislativo não se desvendam ao primeiro olhar.

A dificuldade e/ou negligência do poder público, seguidos do descompromisso dos proprietários em cumprir as legislações, desencadeou um desastre não como obra de um acaso, mas resultado de uma série de omissões. Sinalizando que a infraestrutura e o gerenciamento das normas de segurança demandam observação e questionamento, para além da condescendência e a aceitação acrítica aos modismos sociais e à fetichização do lazer. Contudo, evidencia que a aparência, a exterioridade é obtusa sem a interioridade e que os estabelecimentos privados não são sinônimos de segurança.

A mobilização do poder público, posterior ao desastre, na criação de novas legislações que garantissem a segurança nas danceterias, em especial a Lei Kiss, foi um marco no país, possibilitando tornar mais efetivas as ações em prol da população, em especial, o direito à segurança. Contraditoriamente, a flexibilização da Lei Kiss explicitou que o sistema econômico e interesses privados permanecem sendo os grandes balizadores da política, das relações de força, de hegemonia e, consequentemente, das relações entre o público e o privado.

Minimizar a importância das leis criadas para assegurar a segurança nas danceterias é um equívoco, bem como acreditar que elas são a solução final para a prevenção de incêndios ou desastres semelhantes ao da Boate KISS. Ao contrário, demanda em conjunto, 
ações de conscientização da população, aplicação das leis, investimento nos setores de fiscalização e capacitação profissional, a fim de fomentar uma cultura de segurança. Os aspectos legislativo, técnico e de conscientização individual e geral precisam estar articulados e serem levados à expressão máxima.

Afinal, o desastre da Boate KISS inestimável para os familiares e para quem o viveu, não pode ser esquecido pelo conjunto social. Foi um evento que registrou tanto a gravidade de riscos na esfera do lazer e nas tecnologias que incitam desejos, especialmente, sob a lógica do lucro, quanto a necessidade de garantia de direitos sociais e de equidade social.

\section{REFERÊNCIAS}

BECK, Ulrich. Sociedade de Risco. 2. ed. São Paulo: Editora 34, 2011.

COUTINHO, Carlos Nelson. De Rousseau a Gramsci: ensaios de teoria política. São Paulo: Boitempo, 2011.

DENARDIN, Vanessa Cibele Cauzzo, SILVA, Adriana Pissoni. Paisagem urbana e hospitalidade pública um estudo em praças de Santa Maria, RS. Disciplinarum Scientia. v. 6, n. 1, p. 85-96, 2010.

DIÁRIO DE SANTA MARIA. Santa Maria, Rio Grande do Sul, Brasil, jan./dez. 2013. DIÁRIO DE SANTA MARIA. Santa Maria, Rio Grande do Sul, Brasil, jan./dez. 2014.

FRANCO, Maria Laula P.B. Análise do Conteúdo. 2. ed. Brasília: Liber Livro Editora, 2005. GUIDDENS, Anthony. Mundo em Descontrole: o que a globalização está fazendo em nós. 6ed. Rio de Janeiro: Record, 2007.

INQUÉRITO POLICIAL n. ${ }^{\circ}$ 001/2013/3a Delegacia de Polícia Regional. MARIN, Elizara Carolina; PADILHA, Valquíria. Lazer e consumo no espaço urbano. In: Ana Cristina P.C. de ALMEIDA; Lamartine P. COSTA. (Ed.). Meio Ambiente,

Esporte, Lazer e Turismo: estudos e pesquisas no Brasil. Rio de Janeiro: Gama Filho, p.289-298, 2007.

MASCARENHAS, Fernando. Entre o ócio e o negócio: teses acerca da anatomia do lazer.

2005. 305 p. Tese (Doutorado em Educação Física). Campinas: Faculdade de Educação Física, Universidade Estadual de Campinas, 2005.

. Lazer e trabalho: liberdade ainda que tardia. In: Seminário o lazer em debate, 2., 2001. Belo Horizonte. Coletânea... Belo Horizonte: UFMG/DEF/CELAR; 2001; p. 81-93. . O pedaço sitiado: cidade, cultura e lazer em tempos de globalização. Rev. Bras. Cienc. Esporte, v. 24, n. 3, p. 121-143, 2003.

NASCIMENTO, Thaiane Bonaldo; MARIN, Elizara Carolina. Lazer e juventude: relações de segurança e risco em danceterias. Licere; v.18, n. 4, p. 341-363, 2015.

PADILHA, Valquíria. Consumo e lazer reificado no universo onírico do shopping center. In: Padilha, V. (Org.). Dialética do Lazer. São Paulo: Editora Cortez, 2006, p. 126-156. PADILHA, Valquíria. Desafios da crítica imanente do lazer e do consumo a partir do shopping center. Artcultura, v.10, n.17, p.103-119, 2008. 
PONTES, Alexandre Kerr. Juventude e Risco: Problematizando o sentido construído por esta relação. 2011. 142p. Dissertação (Mestrado em Psicologia). Fortaleza: Programa de Pós-Graduação em Psicologia, Departamento de Psicologia, Universidade Federal do Ceará, 2011.

RIO GRANDE DO SUL. Lei complementar no 14.376, de 26 de dezembro de 2013.

Assembleia Legislativa do Estado do Rio Grande do Sul. Porto Alegre, 26 dez. 2013.

SALDANHA, Mateus. Formulando políticas públicas do esporte e lazer no âmbito da cidade. In: Congresso Brasileiro de Ciências do Esporte, 13., 2003, Anais... Caxambu. 2003. p. 1-7.

SPINK, Mary Jane Paris. Suor, Arranhões e Diamantes: as contradições do risco na Modernidade Reflexiva. 2002a. Disponível em: http://www4.ensp.fiocruz.br/projetos/ esterisco/suor1.htm. Acesso em: 23 maio 2013.

SPINK, Mary Jane Paris, MEDRADO, Benedito., MELLO, Ricardo Pimentel. Perigo, Probabilidade e Oportunidade: a linguagem dos riscos na mídia. Psicologia: Reflexão e Crítica, v. 15, n. 1, p. 151-164, 2002b.

Recebido em: Outubro/2017

Aprovado em: Fevereiro/2018 